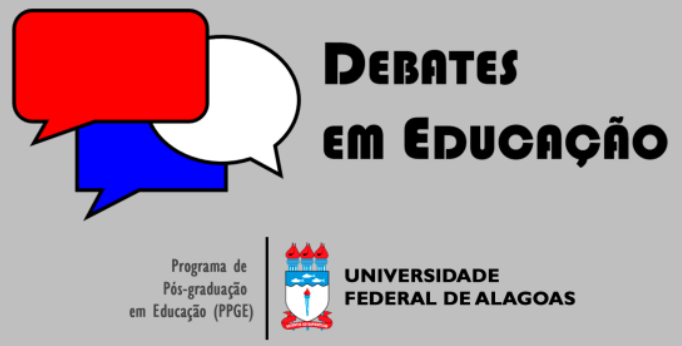

ISSN Eletrônico 2175-6600

Vol. 12 | Número Especial | 2020

Fernando Rossetto Gallego Campos

Instituto Federal de Santa Catarina (IFSC)

Universidade Federal da Fronteira Sul (UFFS)

fernando.campos@ifsc.edu.br

Suzana Rovadoscki

(9) iD

Instituto Federal de Santa Catarina (IFSC)

suzanaro@gmail.com

\section{MÚLTIPLAS LEITURAS: ADAPTAÇÕES FÍLMICAS DE CONTOS DE EDGAR ALLAN POE EM AULAS DE INGLÊS}

\section{RESUMO}

Este estudo tem como objetivo discutir, a partir de observação docente e percepção discente, como um conjunto de aulas de Língua Inglesa que resultou em produções audiovisuais baseadas em textos literários, foi capaz de promover múltiplas leituras. $\bigcirc$ estudo foi conduzido em quatro etapas: exibição de filme adaptado de um conto de Poe; oficinas literárias com contos deste autor; produção de filmes adaptados de contos de Poe pelos alunos; exibição das produções. Os informantes foram 37 alunos do Ensino Médio de uma escola pública. A observação docente foi feita ao longo do estudo e a percepção discente foi coletada por um questionário depois da primeira etapa e outro depois da exibição das produções discentes. Os alunos relataram aumento de interesse pela leitura de literatura e desenvolvimento de habilidades na língua inglesa. Os resultados mostraram que o conjunto de aulas e atividades ajudou a desenvolver múltiplas leituras, como a literária e a fílmica.

Palavras-chave: Leitura. Literatura. Cinema.

\section{MULTIPLE READINGS: FILM ADAPTATIONS OF EDGAR ALLAN POE TALES IN ENGLISH CLASSES}

\begin{abstract}
This study aims to discuss, based on teacher observation and student perception, how a set of English language classes which resulted in audiovisual productions based on literary texts, was able to promote multiple readings. The study was conducted in four stages: screening of a film adapted from a short story by Poe; literary workshops with tales by this author; production of films adapted from Poe's short stories by students; exhibition of productions. Participants were 37 high school students from a public school. The teacher observation was made throughout the study and the student's perception was colleted by a questionnaire after the first stage and another after the exhibition of the student production. Students reported increased interest in reading literature and a developing English language skills. Results showed that the set of classes and activities helped to develop multiple readings, such as literary and film.
\end{abstract}

Keywords: Reading. Literature. Cinema.

Submetido em: 15/04/2020

Aceito em: 18/05/2020

Publicado em: 10/12/2020

do http://dx.doi.org/| 0.28998/2 I 75-6600.2020v I 2nEspp | 88-204 


\section{INTRODUÇÃO}

Historicamente, um dos maiores desafios da escola é de promover a leitura para além do nível instrumental. Neste contexto, o contato com a literatura é uma das principais estratégias utilizadas (ZILBERMAN, 2008). No entanto, a nova geração, apesar de altamente conectada e com grande acesso a informação, está cada vez mais distante da leitura literária (WEBB, 2019). Em escolas públicas, sobretudo, fora dos grandes centros e em suas periferias, a dificuldade de se trabalhar com literatura é ainda maior, devido ao baixo contato dos alunos com o texto literário (ZILBERMAN, 2008). Se esta dificuldade é grande na leitura de obras literárias em língua portuguesa, é ainda maior em obras em língua inglesa, pois além da falta de contato, hábito e gosto, há o desafio da compreensão leitora.

Apesar de os alunos terem cada vez mais contato com as tecnologias da informação, bem como se interessado por produções audiovisuais, o uso de filmes em sala de aula é comumente visto como algo apenas para preencher uma aula vaga ou como uma falha no planejamento do professor (CRISTÓVÃO, 2007). Além disso, não é comum que a escola trabalhe na perspectiva da alfabetização filmica, ou seja, a fim de desenvolver nos alunos instrumentos para a leitura de obras cinematográficas. $\bigcirc$ uso de filmes em sala de aula é uma grande oportunidade para ampliar o conhecimento, uma forma diferenciada de conhecer o mundo, a cultura, a história, a vida, a ciência, o futuro, o passado, a sociedade, etc, mas esse recurso didático ainda é desprezado por educadores e educandos (PACHECO, 20।6). Apesar da pouca preocupação em aproveitar ao máximo todos recursos que o cinema pode oferecer, ele é uma forma de conhecimento com mesmo peso cultural e formativo dos livros e ver filmes é uma prática social tão importante, do ponto de vista da formação cultural e educacional quanto a leitura de obras literárias, filosóficas e sociológicas (DUARTE, 2009). São diversos os estudos que têm demonstrado a efetividade do trabalho em sala de aula através do cinema nas mais diversas áreas (ver BRAGA, 20 I2; FONSECA, 20।4; MUÑOZ-LUNA, 20I4; LAFFERTY, 2016; RAMAN, 2016; ALMEIDA, 2017; SCHURTZ, 2017). Alguns destes trabalhos focam na produção de audiovisuais por parte dos alunos como metodologia de ensino (ver CLAYTON, 2009; JOHNSTON; CHAN, 20I2; RAJENDRAM; GOVINDARAJOO, 20I6).

Portanto, partimos do pressuposto de que o uso do cinema na sala de aula é uma forma de aproximar o aluno da literatura, sendo que o professor pode fazer uso do filme não para substituir a leitura, mas para ajudá-lo a ensinar literatura em aula (VETRIE, 2004), bem como desenvolver outros aspectos da leitura, como a própria leitura fílmica. Além disto, a inclusão de mídias e tecnologias pode motivar os alunos na leitura, usando meios que já lhe são familiares (LIPINER, 20I I). Desta forma, buscar metodologias de ensino que integrem cinema, tecnologia e literatura se torna não apenas importante, mas necessário para oferecer conhecimento de mundo, de história, de cultura. 
O presente estudo tem como objetivo discutir, a partir de observação docente e percepção discente, como um conjunto de aulas de língua inglesa, que resultou em produções audiovisuais baseadas em textos literários, foi capaz de promover múltiplas leituras. $\bigcirc$ estudo foi desenvolvido na Escola de Educação Básica Rudolfo Luzina, escola estadual do município de Nova Erechim-SC, com 37 alunos (20 do sexo feminino e 17 do sexo masculino) do segundo ano do Ensino Médio, com idade entre 15 e 18 anos. Após assistir ao filme Refúgio do Medo (2014), adaptado do conto The System of Dr. Tarr and the Professor Fether, e terem feito uma leitura coletiva do conto The Masque of the Red Death (ambos de Edgar Allan Poe), os alunos, em grupos, realizaram adapções fílmicas de contos do referido autor. A escolha por esse autor se justifica por sua relevância literária, possível interesse dos alunos pelas temáticas e por serem propícios a adaptações filmicas: Poe é um dos autores com maior número de adaptações para o cinema (GERBASE, 2009).

\section{EMBASAMENTO TEÓRICO}

\section{I Literatura e Ensino}

ensino de literatura deve ir além do letramento e da decodificação do texto escrito e também da transmissão de obras consagradas, mas deve trabalhar na perspectiva da formação do leitor (ZILBERMAN, 2008). Nesse sentido, as estratégias e escolhas devem se pautar na aproximação do aluno/leitor ao texto, de forma que, através de sua leitura, mergulhe nos sentidos da obra e que também se motive a procurar outras leituras, inclusive por conta própria.

O ensino de literatura e uso de obras literárias em aulas de língua inglesa são importantes por diversos motivos. A sonoridade, o uso de figuras de linguagem, o estilo de escrita, o vocabulário variado e a interpretação são fatores que aprimoram o aprendizado dos alunos em relação ao idioma e que, ao mesmo tempo, podem enriquecer o conhecimento de mundo dos alunos (CORCHS, 2006). A literatura proporciona uma rica e acessível forma de integração entre o passado e o presente, o que acontece quando o leitor entra em contato com a linguagem literária, que abrange informações variadas sobre filosofia, política, arte, religião de outros países e promove contato com outras formas de pensamento e tradição cultural (BRUMFIT; CARTER, 2000). É através da literatura que o aluno é exposto a temas complexos e novas formas não esperadas da língua (LAZAR, 2004).

A literatura envolve o aluno no enredo podendo ser mais real, por ser um material autêntico, do que alguns falsos diálogos que aparecem muitas vezes em alguns materiais didáticos (LAZAR, 2004). Em aulas de língua inglesa, mesmo alunos de nível básico, conseguem fixar vocabulário, padrões gramaticais e 
melhoram sua capacidade de interpretação já que um texto literário possui riqueza ambígua e metafórica, que desenvolve a habilidade leitora e a busca por informações implícitas nos textos (LAZAR, 2004).

A leitura literária exercita a fantasia e a imaginação, desenvolve a sensibilidade, amplia a visão de mundo, desperta emoções e faz refletir sobre a própria existência (FREITAS, 20। 6). A autora sugere ainda que leitura literária é uma tarefa cada vez mais desafiadora, necessitando cada vez mais atividades que sejam capazes de desenvolver a leitura produtiva de textos literários e que conduzam o aluno a práticas agradáveis nessa área de ensino-aprendizagem. As práticas de leitura adotadas nas aulas precisam tornar os alunos leitores capazes de dar sentido aos textos de forma crítica e criativa ao mesmo tempo e que, ao escolher textos literários, o professor deve ter em mente a capacidade interpretativa dos alunos e o interesse deles pela temática abordada na obra (FREITAS, 2016).

Mesmo com tantos benefícios para a formação discente, os alunos de Ensino Médio tendem a não se interessar por literatura e a não ter hábito de leitura. Sendo assim, é necessário criar estratégias para que se tornem mais propensos a se interessar por textos literários. Estas estratégias podem estar ligadas ao cinema e à produção audiovisual.

\subsection{Cinema e Ensino}

Gareis (2000) e Brumfit e Carter (2000) apontam a possbilidade de se usar adaptações fílmicas como complemento e suporte para as aulas de literatura, aproveitando as diversas adaptações de romances para o cinema. Acrescentam, ainda, que os alunos podem desenvolver vídeos com base na leitura. Nesta perspectiva, "O aluno é um agente ativo em sala de aula e não um receptor passivo. É essencial para nós que as atividades provoquem interação entre leitores e texto [...] e entre os leitores mesmos, incluindo o professor" (DUFF; MALEY, 2003, p. 5).

Segundo Cristóvão (2007), há uma série de questionamentos a serem feitos quando o filme é apresentado como uma atividade escolar: se é adequado para a série; se está no programa do estabelecimento de ensino; se não é apenas para matar aula. A autora ainda lembra que muitos alunos preferem assistir a um filme a ler um livro, mas relembra que, ao assistir a um filme, o aluno também faz a leitura de imagens e de sons para compreender seus sentidos. Assim, os alunos se sentem motivados a ampliar seu conhecimento da língua alvo de forma dinâmica e divertida, e o professor se sente livre para propor atividades que explorem práticas da leitura, oralidade, escuta e escrita. Moran (1995, p. I) afirma que: "Um bom filme é interessante para introduzir um novo assunto, para despertar a curiosidade, a motivação para novos temas. Isso facilitará o desejo de pesquisa dos alunos para aprofundar o assunto do filme e da matéria". O autor aponta que ao utilizar recursos de multimídia, a construção do conhecimento fica mais livre, dá maior abertura e fica menos rígida. 
Segundo Migliorin (201 I, p. 132), o professor deve "sair do lugar daquele que ensina para experimentar com os alunos", dar autonomia aos mesmos para aprender com eles esta linguagem de imagens e movimentos. $\bigcirc$ cinema deve ir além da instrumentalização do uso do filme para ensinar diferentes disciplinas, sendo "muito mais do que isto, o cinema é um projeto, que engloba diferentes e infinitos projetos" (PACHECO, 2016, p. 92). Para Bergala (2008, p. 125), "os filmes passam de mero suporte pedagógico de disciplinas e conteúdos para uma vivência cultural escolar, uma iniciação à arte". Bergala (2008) e Fresquet (2013) convocam os alunos a pegarem suas câmeras e viverem experiências cinematográficas dentro da sala de aula. Para eles, a entrada do cinema na escola provocaria uma prática de vivência escolar.

Fresquet (2013, p. 32-34) sugere que as escolas sejam escolas de cinema, para que os alunos e professores produzam filmes visando as "práticas de emancipação intelectual ética e estética", que deixem de ter "função social de moralizar, disciplinar e instruir" e passem a ser "espaço de comunicação e troca de aventuras intelectuais afetivas e sensíveis". Um estudo de Bastos, Rezende Filho e Pastor Junior (20 I 5), mostra a efetividade de um trabalho de produção de audiovisuais com alunos de Licenciatura em Biologia, mas demonstra que houve leves discrepâncias entre os significados concebidos pelos autores do vídeo e pelos espectadores (colegas de turma). Tal questão pode estar ligada a uma baixa exposição prévia dos alunos, em ambiente escolar, com o desenvolvimento da competência para ver (DUARTE, 2009). incipiente trabalho no sentido da análise e leitura fílmica vem de uma defasagem na formação de professores para se trabalhar a alfabetização fílmica, como indica o estudo de Santos, Gordo e Santos (2020), entre professores de escola pública.

\section{METODOLOGIA}

O estudo foi realizado nas aulas de língua inglesa, do segundo ano do Ensino Médio, da Escola de Educação Básica Rudolfo Luzina, escola estadual do município de Nova Erechim-SC, na Região Intermediária de Chapecó. A partir de um conjunto de aulas, o estudo foi conduzido em quatro etapas: (I) exibição de um filme adaptado de um conto de Edgar Allan Poe; (2) desenvolvimento de oficinas literárias a partir de contos desse autor; (3) produção de filmes adaptados de contos do autor pelos próprios discentes; e, (4) exibição das produções. A primeira etapa ocorreu no contraturno das aulas regulares dos alunos envolvidos. Já a segunda e a quarta etapas, foram desenvolvidas durante as aulas de Língua Inglesa. A terceira etapa foi realizada em grupos em horários e locais definidos pelos alunos de cada um dos grupos.

A primeira etapa, desenvolvida na escola, no contraturno, contou com a participação de 36 alunos (20 do sexo masculino e 16 do sexo feminino), com idade entre 15 a 18 anos. Nessa noite, os alunos 
assistiram ao filme Refúgio do Medo (20 I 4), baseado no conto de Edgar Allan Poe: The System of Dr. Tarr and the Professor Fether e participaram de um debate conduzido pela professora-pesquisadora sobre aspectos da obra cinematográfica. Depois do debate, na própria aula, os 36 alunos responderam a um questionário com 15 perguntas ( 3 abertas e 12 fechadas). $\bigcirc$ objetivo do questionário era apreender as experiências dos alunos com filmes, seus hábitos de leitura e seus conhecimentos sobre Edgar Allan Poe, autor que seria trabalhado nas oficinas.

A segunda etapa, desenvolvida em quatro aulas de Língua Inglesa de 50 minutos, contou com a participação de toda a turma: 37 alunos (20 do sexo feminino e 17 do sexo masculino). Na primeira aula, foram exploradas, em inglês, algumas questões a respeito de Edgar Allan Poe para verificar o conhecimento prévio dos alunos. Posteriormente, foi lido um texto biográfico sobre o autor. Depois da leitura, os alunos realizaram algumas atividades para exploração do vocabulário e a professora-pesquisadora contextualizou literariamente Edgar Allan Poe e sua obra, apresentando sua vida e sua relação com temas abordados na obra do autor (suspense, sobrenatural e mistério). Sob a orientação da professora-pesquisadora, os alunos comentaram sobre o que leram e compararam com o que haviam assistido no filme Refúgio do Medo (20।4). Nessa mesma aula, foi assistido um vídeo sobre a obra de Edgar Allan Poe (FELTRIN, 20।6).

Na segunda aula, a professora-pesquisadora apresentou o texto original do conto The Masque of the Red Death, de Edgar Allan Poe. Este foi lido pela professora-pesquisadora em voz alta e projetado em slides (texto digitado e dividido em vários slides). Durante a leitura, foram feitas paradas para explicar o vocabulário e fazer pequenas inferências, já que a maioria dos alunos estava lendo e ouvindo um conto em língua inglesa pela primeira vez.

Na terceira aula, os alunos assistiram a um curta-metragem disponível no Youtube do conto The Masque of the Red Death (2007). A maioria dos alunos conseguiu novamente perceber as marcas dos contos de Edgar Allan Poe. Como tarefa de casa, os alunos foram desafiados a lerem outro conto de Edgar Allan Poe, em português ou em inglês (opção encorajada pela professora-pesquisadora). Muitos relataram que, além de lerem, assistiram a pequenas produções audiovisuais no Youtube.

Na quarta aula, os alunos, em posse de conto escolhido e/ou sugerido pela professora, juntamente ao seu grupo, organizaram a leitura, debate, contextualização do conto, bem como pesquisa sobre ele. A partir do estudo das características do gênero roteiro de cinema, os alunos aparentaram se apropriar parcialmente da técnica. Assim, selecionaram a parte da obra a ser adaptada, escreveram a sinopse dessa adaptação, descreveram as características principais de cada uma das personagens e, posteriormente, transformaram essa história em um roteiro para curta-metragem. Como se percebeu que alguns alunos não dominavam a edição de filmes, foi trabalhada uma oficina de edição de vídeo (quarto momento da primeira etapa), usando o editor do Windows. 
A terceira etapa foi a produção do audiovisual em si, que envolveu diversos processos: leitura e releitura do conto (com supervisão da professora), que pode ser feito em língua inglesa ou língua portuguesa; divisão das funções entre os integrantes do grupo (direção, atuação, edição, etc.), a partir dos interesses e aptidões destes; roteirização do conto ou de um trecho; filmagem e edição. Os grupos tiveram cerca de um mês para realizarem esta etapa e receberam suporte técnico do assistente de laboratório de informática para eventuais problemas com a edição do filme.

A quarta etapa consistiu em: ( I ) exibição dos audiovisuais produzidos para os colegas da turma; (2) aplicação de questionário a fim de captar as percepções dos alunos em relação ao conjunto de aulas (etapas I a 4); (3) avaliação oral do conjunto de aulas e atividades realizadas. Todas estas atividades foram realizados no mesmo encontro (duas aulas geminadas de 50 minutos), em uma sala com projetor. Primeiramente, foram exibidos os sete filmes produzidos pelos alunos. Posteriormente, os alunos responderam um questionário com 15 perguntas (7 abertas e 8 fechadas) e apresentaram oralmente impressões sobre a intervenção realizada. Participaram desta etapa 37 alunos (20 do sexo feminino e 17 do sexo masculino), um aluno a mais do que na primeira etapa.

\section{RESULTADOS E DISCUSSÕES}

\section{I Primeiro questionário}

Os dados coletados no primeiro questionário, junto aos alunos que assistiram previamente o filme Refúgio do Medo (20।4), consistiram em obtenção das primeiras impressões dos alunos em relação ao filme assistido e à leitura em Inglês de contos de Edgar Allan Poe. Neste momento, realizado no contraturno, participaram voluntariamente 36 dos 37 alunos da turma (20 do sexo masculino e 16 do sexo feminino).

Na primeira pergunta, 19 alunos (58,3\%) disseram que assistem a filmes às vezes, enquanto 17 alunos (4I,7\%), disseram que assistem sempre. Na pergunta seguinte 19 (52,8\%) alunos responderam que preferem assistir a produções em Língua Inglesa e 17 alunos (47,2\%), que preferem filmes nacionais. Dos 19 alunos que disseram preferir produções em língua inglesa, I I (57,9\%) justificaram sua responta pela qualidade dos filmes e os recursos técnicos utilizados, 3 (I5,8\%) pela grande variedade de lançamentos, 3 ( I5,8\%) porque estas são mais interessantes e divertidas, I (5,3\%) porque gosta da língua inglesa e I (5,3\%) não respondeu o motivo pelo qual prefere produções em língua inglesa. Dos 17 alunos que responderam preferir as produções em língua portuguesa, 14 (82,4\%) justificaram que acham mais fácil entender a língua portuguesa, I (5,9\%) porque assiste por costume, I (5,9\%) porque gosta de escutar a voz dos personagens em português e I (5,9\%) porque não conhece os filmes em língua inglesa. 
Como todos os alunos costumam assistir a filmes (às vezes ou sempre), o uso de cinema em sala de aula é uma boa maneira de baixar o filtro afetivo desses alunos e de mantê-los dispostos a estudar a língua inglesa, já que a maioria (52,8\%) prefere assistir produções em inglês. Mesmo assim, esse é um número relativamente baixo, pois um público adolescente já teria facilidade de assistir filmes legendados e, assim, aproveitar mais as possibilidades de aprendizado com filmes. Ao estimular que os alunos assistam filmes em sua língua original, a escola contribuiria no maior aprendizado de língua estrangeira.

Na terceira pergunta, 32 alunos (88,9\%) responderam que gostaram do filme Refúgio do Medo (20 |4), adaptação do conto The System of Dr. Tarr and the Professor Fether, e 4 ( I I , I \%) disseram que não gostaram

A quarta questão consistia em um conjunto de perguntas fechadas. Algumas delas tinham as alternativas "Sim", "Pouco" e "Não" e outras "Muito", "Pouco" e "Nada". As respostas estão dispostas na Tabela I.

Tabela I - Hábitos de leitura, conhecimento da obra e leitura versus cinema

\begin{tabular}{|c|c|c|c|c|c|c|}
\hline \multirow{2}{*}{ Questão } & \multicolumn{2}{|c|}{ Muito/sim } & \multicolumn{2}{|c|}{ Pouco } & \multicolumn{2}{|c|}{ Nada/não } \\
\hline & $N^{0}$ & $\%$ & $N^{0}$ & $\%$ & $N^{0}$ & $\%$ \\
\hline Assistir a filmes pode ajudar no aprendizado de Língua Inglesa? & 23 & $63,9 \%$ & 12 & $33,3 \%$ & I & $2,8 \%$ \\
\hline Já leu um livro porque assistiu a um filme baseado nele? & 16 & $44,4 \%$ & - & - & 20 & $55,6 \%$ \\
\hline Já assistiu a um filme porque leu o livro no qual foi baseado? & 19 & $52,8 \%$ & - & - & 17 & $47,2 \%$ \\
\hline Quanto você gosta de ler? & 13 & $36,1 \%$ & 23 & $63,9 \%$ & - & - \\
\hline Já ouviu falar sobre o escritor Edgar Allan Poe? & 4 & $11,1 \%$ & - & - & 32 & $88,9 \%$ \\
\hline $\begin{array}{l}\text { Quanto você considera que a leitura de contos em inglês ajudaria a } \\
\text { melhorar o seu conhecimento da língua? }\end{array}$ & 23 & $63,9 \%$ & II & $30,6 \%$ & 2 & $5,8 \%$ \\
\hline $\begin{array}{l}\text { Quanto você considera que a produção de vídeos de contos em } \\
\text { inglês ajudaria a melhorar o seu conhecimento da língua? }\end{array}$ & 23 & $63,9 \%$ & 11 & $30,6 \%$ & 2 & $5,8 \%$ \\
\hline
\end{tabular}

Fonte: dos autores.

Dos 36 alunos, $23(63,9 \%)$ responderam que assistir a filmes pode ajudar muito no aprendizado de Língua Inglesa, 12 (33,33\%) que pode ajudar pouco e I (2,8\%) disse que não ajuda. Percebe-se que a maioria dos alunos gostam de assistir filmes e identifica no cinema uma possibilidade de aprender e melhorar o seu conhecimento de mundo e língua inglesa. Mais da metade dos alunos - $20(55,6 \%)$ nunca leram um livro porque assistiram a um filme baseado nele. Mas 19 alunos (52,8\%), já assistiram a um filme porque leram o livro no qual foi baseado. Percebe-se que é mais comum, provavelmente pela facilidade e tempo despendido, o aluno apenas assistir ao filme e não procurar a obra que o originou. Mesmo assim, a maioria dos alunos relatou que já leu um livro no qual foi baseado um filme.

A maior parte dos alunos - 23 (63,9\%) - respondeu que gostam muito pouco de ler, enquanto apenas $13(36,1 \%)$ afirmaram que gostam. Observa-se a falta de hábito de leitura, mesmo de alguns dos que responderam que já leram um livro no qual foi baseado um filme (provavelmente o fizeram ou por obrigação ou de maneira esporádica). Esse problema é potencializado pelos poucos momentos de leitura 
na escola, pelo baixo número de aulas de literatura (inclusive em língua portuguesa) e pela priorização de obras cobradas em vestibulares ou mesmo distantes do gostos de adolescentes. Oferecer diversos gêneros literários seria uma forma de conquistar e motivar novos leitores.

A maioria dos alunos - 32 (88,9\%) - revelou que nunca tinham ouvido falar em Edgar Allan Poe. O baixo conhecimento do autor e a pouca exposição a obras literárias de autores estrangeiros considerados clássicos é um fator preocupante em estudantes de escola pública que já têm aulas de língua inglesa desde o Ensino Fundamental. Apesar de 23 alunos (63,9\%) terem julgado que a leitura de contos em inglês ajudaria muito a melhorar o conhecimento da língua inglesa, II alunos (30,6\%) responderam que ajudaria pouco e 2 alunos (5,8\%) que não ajudaria. Isto demonstra certa resistência em relação à leitura, que pode estar ligada a experiências prévias.

Os resultados se repetiram quando os alunos foram perguntados se a produção de um audiovisual baseado em contos em inglês ajudaria na aprendizagem da língua inglesa: 23 alunos (63,9\%) responderam que ajudaria muito, I I alunos (30,6\%), pouco e 2 alunos (5,8\%) que não ajudaria. Acredita-se que, como não haviam tido experiência anterior na produção de audiovisual, os alunos não tinham boas expectativas quanto aos resultados das atividades propostas.

\subsection{Segundo questionário}

O segundo questionário foi respondido pelos 37 alunos que participaram das três últimas etapas do estudo. Ele foi aplicado logo após a exibição dos audiovisuais produzidos pelos alunos. Seu objetivo era apreender as percepções dos alunos em relação ao conjunto de aulas e atividades realizadas, seu aprendizado e suas experiências.

Uma das atividades era ler um conto de Edgar Allan Poe a fim de realizar a adaptação fílmica. Para tal, os alunos podiam escolher ler o conto em sua versão original (em inglês), ou sua tradução para português. Para a elaboração das produções audiovisuais, 28 alunos $(75,7 \%)$ escolheram ler a versão do conto traduzida para o português. Desses, 17 alunos (60,7\%) alegaram que usaram essa versão porque tiveram dificuldade de entender a história em inglês, 8 alunos (28,6\%) porque tiveram interesse em comparar as versões em inglês e em português, e 3 alunos (10,7\%) porque tiveram dificuldade de entender o vocabulário específico da obra. Além dos 8 alunos que compararam as versões original (em inglês) e a traduzida (em português), 7 alunos (18,9\%) leram a versão em inglês para elaboração do audiovisual. Destes, 4 alunos (57, I\%) disseram que não sentiram necessidade de buscar uma versão em português e 3 alunos (42,8\%) que preferiram usar a referência dada pela professora. 2 alunos (5,4\%) não responderam se leram o conto em português ou em inglês. Como foi a primeira atividade desse tipo realizada, a falta de segurança com relação ao entendimento do texto por parte da maioria dos alunos 
pode ter sido um dos fatores que levaram tantos alunos a procurarem a versão em português do conto escolhido. No entanto, I 5 alunos (40,5\%) tiveram contato direto com leitura em língua inglesa, pois leram exclusivamente o conto na versão original ou leram, tanto em inglês, quanto em português. É possível que em próximas atividades semelhantes, os alunos se sintam mais confiantes em ler em inglês.

A maioria dos alunos revelou que não buscou ler outras obras de Edgar Allan Poe durante o período da aplicação do conjunto de aulas - 34 (91,9\%) -, mas que talvez lerá obras do autor depois da conclusão das atividades propostas - 35 (94,6\%) - e que continuará ler obras em inglês de Edgar Allan Poe ou outros autores - 25 (67,6\%). O fator tempo pode ter influenciado no baixo número de alunos que leram outras obras do autor, mas a falta de hábito de leitura e a pouca exposição à língua inglesa durante as aulas (considerando toda trajetória escolar) podem ter sido as causas principais. Por outro lado, o número de alunos que pretendem continuar lendo (ou Edgar Allan Poe ou obras em inglês) é animador, pois supera a quantidade de alunos que haviam respondido ter hábito de leitura, o que mostra que possivelmente o conjunto de aulas, ao menos, despertou curiosidade por literatura em alguns alunos.

Os resultados da percepção dos alunos em relação à melhoria das habilidades em língua inglesa estão dispostos na Tabela 2. Apesar de a maioria ter respondido "pouco" nas três habilidades, observa-se que há poucos alunos que não perceberam nenhuma melhora, sobretudo, nas habilidades de produção oral $(8,1 \%)$ e de compreensão (18,9\%).

Tabela 2 - Percepção dos alunos quanto à melhoria nas habilidades em língua inglesa

\begin{tabular}{lcccccc}
\multicolumn{1}{c}{ Questões } & \multicolumn{2}{c}{ Muito } & \multicolumn{2}{c}{ Pouco } & \multicolumn{1}{c}{ Nada } \\
\cline { 2 - 6 } & $N^{0}$ & $\%$ & $N^{0}$ & $\%$ & $N^{0}$ & $\%$ \\
\hline $\begin{array}{l}\text { Você percebeu melhora na sua habilidade de produção oral } \\
\text { (ficou mais atento no momento da pronúncia das palavras)? }\end{array}$ & 8 & $21,6 \%$ & 26 & $70,3 \%$ & 3 & $8,1 \%$ \\
\hline $\begin{array}{l}\text { Você percebeu melhora na sua habilidade de ouvir } \\
\text { (compreensão oral)? }\end{array}$ & 8 & $21,6 \%$ & 22 & $59,5 \%$ & 7 & $18,9 \%$ \\
\hline Você percebeu melhora com relação à sua leitura em inglês? & 6 & $16,2 \%$ & 21 & $56,8 \%$ & 10 & $27,0 \%$ \\
\hline
\end{tabular}

Fonte: dos autores.

A produção oral foi a habilidade com maior percepção de aprendizado: 34 alunos (91,9\%) responderam que perceberam melhora, sendo 8 muito $(21$,6\%) e 26 pouco (70,3\%). Esta percepção de melhora foi motivada pela necessidade de os alunos falarem em inglês nas suas produções audiovisuais. Por outro lado, alguns alunos não possuíam falas nos filmes (por não terem atuado e, portanto, assumido outras funções, como direção e operação de câmera), o que pode explicar que nem todos tenham percebido melhora na habilidade. Indicamos que, nas próximas atividades dessa natureza, seria recomendável que todos os alunos tivessem falas nas produções audiovisuais, como forma de estimular o desenvolvimento da habilidade oral de todos os alunos.

Os resultados acerca da percepção de aprendizado da habilidade de compreensão oral tiveram resultados parecidos com a da produção oral. $\bigcirc$ número de alunos que perceberam que a habilidade 
melhorou muito foi o mesmo: 8 (21,6\%). A diferença é que 22 (59,9\%) responderam perceberem pouca melhora versus 26 (70,3\%) que perceberam pouca melhora na habilidade de produção oral. É possível que esse menor número esteja relacionado com a falta de associação dos alunos dessa percepação a atividades realizadas antes da produção do audiovisual, como assistir ao filme Refúgio do Medo em língua inglesa (legendado) e ouvir o conto The Masque of the Red Death em inglês.

Já a habilidade de leitura foi a que registrou menor percepção de aprendizado: 27 alunos (73,0\%) responderam que perceberam melhora, sendo 6 muito (16,2\%, o menor percentual das três habilidades analisadas) e 2 I pouco (56,8\%, também o menor percentual se comparado com as demais habilidades). Um dos fatores que explicam a menor porcentagem foi que menos da metade dos alunos - I5 (40,5\%) - fizeram a leitura do conto em sua versão original. No entanto, percebe-se que as atividades de leitura foram além da leitura do conto em si, pois $73,0 \%$ responderam que perceberam melhora na habilidade de leitura. Essa percepção de melhora pode estar ligada ao contato dos alunos com outros gêneros textuais em língua inglesa além dos literários, como tutoriais para produção, filmagem e/ou edição do filme.

Ao responderem ao questionário, todos os alunos afirmaram que o conjunto de aulas melhorou seu relacionamento com a língua inglesa. Nessa questão aberta, as explicações fornecidas do porquê, foram que: tiveram bastante contato com a língua; sentiram-se confortáveis realizando o trabalho; gostaram de procurar coisas novas nas atividades de língua inglesa; ficaram mais interessados em filmes legendados. Seguem algumas citações de respostas: "Sim, pois é uma atividade diferente das que tínhamos. E também porque me desafiei a tentar entender o texto em inglês!" e "Sim. pois aprendi coisas novas e que o inglês vai muito além da sala de aula. Ele está presente em tudo.". Percebe-se a melhora da percepção dos alunos em relação à língua inglesa, bem como em relação à sua autoestima, o que pode ser aproveitado para se trabalhar diversos conteúdos e habilidades. Além disso, os alunos passaram a perceber que o inglês está presente no seu cotidiano, o que pode tornar o aprendizado mais efetivo e significativo. Utilizar materiais autênticos e tecnologias audiovisuais, que fazem parte da vida dos alunos, pode os incentivar no estudo da língua inglesa e os desafiar a procurar outras formas de melhorar o seu relacionamento com a língua.

Apenas 6 alunos (16,2\%) responderam que não tiveram dificuldades na atividade. Dos 31 alunos $(83,8 \%)$ que responderam que tiveram dificuldades: 13 (4I,9\%), atribuíram a maior dificuldade à leitura de uma obra em inglês; 7 (22,6\%), à pronúncia das palavras em língua inglesa; 4 (12,9\%), à edição do vídeo; 3 (9,7\%), a reunir os colegas fora da escola; I (2,7\%), a fazer cenas inteligíveis ao público; I (3,2\%), à produção de um roteiro; I (3,2\%), a traduzir as palavras; e I (3,2\%), à organização do cenário e atuação. Percebe-se que a maioria das dificuldades apontadas - por 21 alunos $(67,7 \%)$ - se referem ao uso da língua inglesa, o que demonstra que o conjunto de aulas e atividades fez com que os alunos saíssem da zona de conforto e buscassem melhorar habilidades. Nesse grupo se destaca a dificuldade de leitura 
(33,3\% dos que apontaram sua maior dificuldade relacionada à língua inglesa), demonstrando, novamente, a falta de hábito de leitura, quanto mais em inglês. Por outro lado, 10 alunos (32,3\% dos que citaram dificuldades), apontaram que as maiores dificuldades foram em relação à produção do audiovisual, o que não significa que os alunos não tiveram dificuldades com o uso da língua inglesa, mas que, provavelmente, se empenharam em funções mais técnicas. Tais dificuldades estão relacionadas à própria natureza da produção audiovisual, mas são potencializadas pelo fato de ter sido o primeiro contato de muitos com esse tipo de atividade. Aqui, percebe-se também a dificuldade de assimulação não apenas de processos técnicos, mas também de características da linguagem cinematográfica/audiovisual.

Quando questionados sobre o que mais gostaram do conjunto de aulas e atividades, 28 alunos responderam. Destes, 7 alunos (25\%) declararam que foi gravar; 6 (21,4\%), que foi conhecer outras obras do autor; 5 ( I7,9\%), assistir ao trabalho de outros grupos; 4 (| $4,3 \%)$, interagir com os colegas; 3 (10,7\%), atuar. Conseguir narrar uma história em inglês; pesquisar palavras novas; e ter feito algo que nunca tinha feito nas aulas de inglês foram aspectos citados, cada um deles, por um aluno (3,6\% cada). Algumas das declarações foram: "Gostei muito, pois fiquei em contato com a língua inglesa de uma maneira que nunca tinha imaginado! E entendimento na sala de aula de maneira diversificada!"; "Foi muito interessante pois nunca tinha feito nada parecido. Aprendi muito também"; "É uma nova experiência e foi bom para entender um pouco de cada história."; e "Foi algo novo. Despertou um pouco mais meu interesse pela matéria". Observa-se o quanto o uso da metodologia aliando diferentes leituras - de gêneros literário e cinematográfico - motivou os alunos, que puderam aprender de forma lúdica e significativa, aumentando seu gosto pela língua inglesa, mas também por literatura e por cinema.

Os desafios oferecidos aos alunos para que usassem mais a língua inglesa e a unissem às tecnologias utilizadas por eles no dia a dia, proporcionou uma busca de conhecimento e superação de dificuldades para se chegar à produção de audiovisuais. Na percepção dos alunos, o trabalho em grupo foi fundamental para o sucesso da atividade e para a qualidade do material produzido. Como se tratava de trabalho extenso e que buscava desenvolver uma série de habilidades em língua inglesa, bem como promover o contato dos alunos com a literatura, a alfabetização fímica e a produção audiovisual, trabalhar em grupo não apenas viabilizou as atividades propostas, mas também trouxe maior segurança aos alunos, bem como um ambiente mais propício para que baixassem o filtro afetivo e pudessem se expressar mais livremente.

\subsection{Múltiplas literaturas no conjunto de aulas e atividades realizadas}

Aspectos relacionados a múltiplas leituras propiciadas pelo conjunto de aulas e atividades foram apreendidas a partir das observações docentes e também direta ou indiretamente pelos questionários aplicados. Destacamos alguns aspectos: a leitura instrumental em língua inglesa, a leitura literária, a leitura 
fílmica, a leitura de obras cinematográficas como adaptação de obras literárias e o gosto pela leitura (seja ela literária ou fílmica).

As questões ligadas à leitura instrumental em língua inglesa (reading) já foram discutidas na seção anterior, mas cabe retomar alguns aspectos, pois se relacionam com outros aspectos citados. Percebemos desenvolvimento na capacidade dos alunos de lerem em língua inglesa, não apenas através de aumento de competência técnica, mas também pela ampliação do repertório de gêneros textuais, já que atividades que envolveram literatura em língua inglesa eram inéditas na formação escolar dos alunos. Assim, a questão instrumental, apesar de não se bastar em si como objetivo educacional, propicia que o aluno consiga acessar obras literárias, expanda seus gostos e hábitos de leitura (ler obras na língua original, por exemplo), bem como amplie sua visão de mundo.

A questão da leitura literária foi tangenciada durante todo o texto, mas alguns aspectos aqui precisam ser frisados. Um deles é o contato com um texto literário original, algo infelizmente pouco comum para a geração $Z^{\prime}$, que mantém contato com outros gêneros textuais, normalmente medidos por tecnologia (WEBB, 2019). Esse contato é o primeiro passo para aumentar o capital acadêmico e cultural dos alunos (WEBB, 2019). Outro é a fuga do simples pragmatismo de se ler uma obra literária simplesmente para a realização de uma avaliação, o que promove ainda maior resistência por parte dos alunos, inclusive daqueles que já têm hábito de leitura. Apesar da leitura do um conto de Edgar Allan Poe tenha sido condição sine qua non para a realização da atividade (que foi avaliada), o planjamento e a execução do conjunto de aulas se preocuparam que a leitura fosse uma "atividade propiciadora de uma experiência única como texto literário" (ZILBERMAN, 2008, p. 16), ou seja, o aluno devia ir além do ato de ler, mas interpretar, imaginar e materiailizar sua leitura através da representação fílmica. Finalmente, temos o aspecto do exercício da análise na leitura literária, pois por mais que não tenha sido cobrada diretamente uma análise literária, os alunos tiveram que identificar elementos - como narrativa, personagens, diálogos - a fim de compreender o conto e, posteriormente, adaptá-lo para a linguagem filmica.

Tal adaptação também pressupõe certo domínio de linguagem fílmica por parte dos alunos. Como a literatura indica e os questionários apontaram, os alunos têm mais contato com a linguagem fílmica do que a literária no seu cotidiano, mas isso não significa que tenham "competência para ver" (DUARTE, 2009, p. 13). Tal termo, emprestado de Bourdieu, expressa "certa disposição, valorizada socialmente, para analisar, compreender e apreciar qualquer história contada em linguagem cinematográfica", algo que se desenvolve pelo contato com as artes e com as mídas, mas também em ambiente escolar (DUARTE, 2009, p. 13). Nesse contexto,o filme pode ser encarado como um texto, pois materializa um discurso

\footnotetext{
1 Também chamados de nativos digitais, os membros da geração $Z$ são os nascidos entre a segunda metade dos anos 1990 e o começo da década de 2010. Esta geração se caracteriza por ter nascido em uma era de grande difusão e variedade de mídias e tecnologias digitais de informação.
} 
utilizando determinados códigos, em uma linguagem própria: a cinematográfica (WILKE; RIBEIRO; OLIVEIRA, 2003). Portanto, a leitura fílmica é algo que pode (e deve) ser desenvolvida na escola (BERGALA, 2008; FRESQUET, 2013), o que pode ser feito através de exibição, discussão e análise de filmes (o que foi feito na primeira etapa do conjunto de aulas), mas também através da produção de audiovisuais. Neste último caso, articulam-se elementos desenvolvidos pela competência para ver com aspectos técnicos, bem como pressupõe-se certa compreensão das características tanto do texto literário quanto da obra cinematográfica.

Apesar de grande parte dos alunos ter declarado não ter hábito de leitura e que este foi o primeiro trabalho de produção audiovisual no seu percurso escolar, a estratégia de se trabalhar a leitura literária e a leitura fílmica através do desafio de se realizar uma adaptação dos contos se mostrou efetiva. Pelas respostas dos alunos, é possível inferir que isso ocorreu porque a atividade ganhou uma dimensão lúdica e porque os grupos se concentraram no produto final (e na sua exibição aos colegas), fatores que tiraram o peso eventual de uma atividade de simplesmente análise literária ou fílmica.

fato de o trabalho ter sido realizado em grupos também contribuiu para que os alunos compartilhassem suas experiências e gostos literários e fílmicos, gerando maior segurança para a realização das tarefas em língua inglesa, mas também estímulos diversos daqueles que tradicionalmente são produzidos na escola, em que as sugestões são feitas pelo professor. Nesse conjunto de aulas e atividades, a leitura literária não se limitou à sua dimensão individual, mas também contemplou sua dimensão social, em que "o leitor tende a socializar a experiência, cotejar as conclusões com as de outros leitores, discutir preferências. A leitura estimula o diálogo, por meio do qual se trocam resultados e confrontam-se gostos." (ZILBERMAN, 2008, p. 17). Tal dimensão social - já mais comum na prática social ligada ao cinema também foi exercitada em relação aos filmes (assistido e produzidos), tendo sido um dos pontos de maior interesse dos alunos na exibição dos filmes.

\section{CONSIDERAÇÕES FINAIS}

Os resultados do presente estudo demonstram que o uso do cinema e da produção de audiovisuais pode ser um fator motivador de leitura de textos em inglês de estudantes nas aulas de Língua Inglesa. $\bigcirc$ conjunto de aulas e atividades quebrou a rotina da sala de aula, utilizando elementos culturais e tecnológicos que estimularam os alunos a se interessarem por literatura e por língua inglesa. Além disso, os alunos participantes: notaram que é possível ler e desenvolver atividades diferenciadas nas aulas; melhoraram o seu conhecimento sobre Edgar Allan Poe e suas características presentes nas obras escritas, sua influência na produção de filmes; ficaram mais conectados, entusiasmados e focados em aprender mais sobre o tópico proposto. 
O conjunto de aulas e atividades propiciou e estimulou uma grande diversidade de leituras pelos alunos, de maneira lúdica e significativa. Dentre as múltiplas leituras, destacamos: a leitura instrumental em língua inglesa, a leitura literária, a leitura fílmica, a leitura de obras cinematográficas como adaptação de obras literárias e o gosto pela leitura (seja ela literária ou fílmica). Tais leituras foram realizadas nas diversas etapas do estudo, mas se articularam, sobretudo, no momento de produção dos audiovisuais.

As salas de aula estão cheias de alunos que gostam de cinema e se interessam por atividades que envolvam tecnologia. É necessário que os professores aproveitem estas possibilidades e ofereçam a eles novas maneiras de aprender a língua inglesa e interagir na sala de aula. Apresentar um autor (aqui: Edgar Allan Poe) que chamasse atenção pelo estilo de escrita aumentou a possibilidade de sucesso nas aulas e a visão da língua e da literatura que muitos dos alunos tinham antes da aplicação do conjunto de aulas e atividades. Outro ponto fundamental foi aproximar os alunos da obra do autor através do cinema, linguagem presente no cotidiano dos jovens. Entretanto, o que tornou o conjunto de aulas e atividades mais efetivo foi que a realização da produção audiovisual colocou os alunos no protagonismo de seu aprendizado, estimulando que aprendessem literatura e língua inglesa em uma situação prática.

A efetividade das atividades propostas poderia ser maior se houvesse mais tempo para que os alunos realizassem a produção audiovisual. Houve necessidade de horas extraclasse para os alunos se reunirem, o que às vezes esbarra no fator locomoção de alunos no contraturno. $\bigcirc$ grande número de alunos que desenvolveram o projeto foi um fator que dificultou a interação maior entre professora e alunos. Muitos alunos poderiam ter avançado mais se tivessem maior orientação e presença da professora junto ao grupo. Espera-se que este artigo contribua para estimular o uso de tecnologias audiovisuais e cinema em sala de aula não apenas para o ensino de Língua Inglesa e Literatura. Entretanto, é fundamental que estas práticas sejam acompanhadas de avaliação dos resultados e reflexão, o que pode gerar novos estudos sobre a temática do uso de tecnologia em sala de aula.

\section{REFERÊNCIAS}

ALMEIDA, R. Cinema e Educação: Fundamentos e Perspectivas. Educação em Revista. Belo Horizonte, v. 33, p. I-28, 2017.

BASTOS, W. G.; REZENDE FILHO, L. A. C.; PASTOR JUNIOR, A. A. Pordução de vídeo educativo por licenciados: um estudo sobre recepção filmica e modos de leitura. Ensaio Pesquisa em Educação em Ciências, Belo Horizonte, v. I7, n. I, p. 39-58, jan/abr. 2015.

BERGALA, A. A hipótese-cinema: pequeno tratado de transmissão do cinema dentro e fora da escola. Rio de Janeiro: Booklink; CINEAD-LISE-FE/UFRJ, 2008.

BRAGA, J. C. F. (org.) Integrando tecnologias no ensino de inglês nos anos finais do ensino fundamental. São Paulo: Edições SM, 2012. 
BRUMFIT, C. J.; CARTER R. A. Literature and language teaching. Oxford: Oxford University Press, 2000.

CLAYTON, P. It's a wrap! A whole school gets behind film-making. NATE Classroom. Spring, 2009.

CORCHS, M. O uso de textos literários no Ensino de Língua Inglesa. Fortaleza: Universidade Estadual do Ceará, 2006.

CRISTÓVÃO, V. L. L. Modelos didáticos de gênero: uma abordagem para o ensino de língua estrangeira. Londrina: UEL, 2007.

DUARTE, R. Cinema \& educação. Belo Horizonte: Autêntica, 2009.

DUFF, A.; MALEY, A. Literature. Resource books for teachers. Oxford: Oxford University Press, 2003.

FELTRIN, T. Biografia: Edgar Allan Poe (Arthur Hobson Quinn) | Mês do Horror - Ano IV. Vídeo do Youtube. Disponível em: < https://www.youtube.com/watch?v=RPdKnIDrjQE > . Acessado em 30 ago. 2018.

FONSECA, M. J. S. Cinema na escolar para quê? Revista Educação e Cultura Contemporânea. Rio de Janeiro, v. 13, n. 31, p. 32-55, 2014.

FREITAS, H. J. M.. A leitura dos clássicos na sala de aula: uma prática possível. Revista Práticas de Linguagem. Juiz de Fora, v. 6, n. I, p. I5-23, jan./jun. 2016.

FRESQUET, A. Cinema e educação: reflexões e experiências com professores e estudantes de educação básica, dentro e "fora" da escola. Belo Horizonte: Autêntica, 2013.

GAREIS, E. Two tumbs up! Forum. Vol. 38, N. I, pp 6, January/March. 2000.

GERBASE, C. O que o cinema aprendeu com Edgar Allan Poe (E o que a literatura ainda aprende com o cinema). Letras de Hoje. Porto Alegre, v. 44, n. 2, p. 21-27, abr./jun. 2009.

JOHNSTON, C.; CHAN, M. Making film vignettes to teach medical ethics. Medical Education. V. 46, p. |133-1134, out. 2012.

LAFFERTY, G. Opening the learning process: the potential role of feature film in teaching employment relations. Australian Journal of Adult Learning. V. 56. I, p. 8-28, abr. 2016.

LAZAR, G. Literature and Language teaching: a guide for teachers and trainers. Cambridge: Cambridge University Press, 2004.

LIPINER, M. Lights, Camera, Lesson: Teaching Literacy through Film. E-Learning and Digital Media. v. 8, n. 4, p. 375-396, 20II.

MIGLIORIN, C. Cinema e escola, sob o risco da democracia. In: FRESQUET, A. (Org.) Dossiê cinema e educação \# I : uma relação de hipótese de alteridade de Alain Bergala. Rio de Janeiro: UFRJ, 20। I.

MORAN, J. O vídeo na sala de aula. Comunicação \& Educação, São Paulo, n. 2, p. 27-35, 30 abr. 1995.

MUÑOZ-LUNA, R. Enhancing language learner's motiviation: the use of routine breakers with undergraduates learning english linguistics. Bellaterra Journal of Teaching \& Learning Language \& Literature. v. 7(I), p. 33-5I, fev-mar. 2014. 
PACHECO, R. Reflexões sobre o campo do cinema e educação. Revista Teias. Rio de Janeiro, v. I7, n. 47, p. 85-100, jan./mar 2016.

RAJENDRAM, S.; GOVINDARAJOO, M. V. Responding to Literature Texts through Films in English and LI with a Multiliteracies Pedagogy. International Journal of Applied Linguistics \& English Literature. v. 5, n. 2, p. 56-63, mar. 2016.

RAMAN, M. G. Reading through films. Advances in Language and Literary Studies. v 7. n I, p. I68- 174 , fev. 2016.

REFÚGIO do Medo. Título Original: Stonehearst Asylum. Direção: Brad Anderson, Produção: Mel Gibson. Intérpretes: Kate Beckinsale, Jim Sturgess, Michael Caine e outros. Roteiro: Joseph Gancemi. Produzido por California Films, 20 I4, DVD ( I 12 min.).

SANTOS, M. A. R.; GORDO, M. E. S. C. SANTOS, C. A. F. Análise fílmica e educação: metodologia e necessidades formativas docentes. Revista Educação e Cultura Contemporânea. Rio de Janeiro, v. 17, n. 47, p. 50-78, 2020.

SCHURTZ, L. W. Batman in the Classroom: Academic Philosophy and "... and Philosophy". Metaphilosophy. v. 48, f. 3, p. 296-303, 2017.

VETRIE, M. Using film to Increase Literacy Skills. English Journal. v. 93 n. 3, p. 39-45, 2004.

VOA Learning English. The Masque of the Red Death by Edgar Allan Poe. 2017. Disponível em: $<$ https://www.youtube.com/watch?v=bu5GV]6z3uk >. Acessado em I I de maio de 2020.

WEBB, J. How to teach english literature: overcoming cultural poverty. Melton: John Catt Educational, 2019.

WILKE, V. C. P.; RIBEIRO, L. B.; OLIVEIRA, C. I. C. A informação potencializada no texto fílmico. DataGramaZero. João Pessoa, v. 4, n. 6, p. I-9, dez. 2003.

ZILBERMAN, R. O papel da literature na escola. Via Atlântica. São Paulo, n. | 4, p. I |-22, dez. 2008.

\section{COMO CITAR ESSE ARTIGO}

\section{Associação Brasileira de Normas Técnicas (ABNT)}

GALLEGO CAMPOS, Fernando Rossetto; ROVADOSCKI, Suzana. Múltiplas leituras: adaptações filmicas de contos de Edgar Allan Poe em aulas de Inglês. Debates em Educação, Maceió, v. I2, p. 188-204, set. 2020. ISSN 2175-6600. Disponível em:

https://www.seer.ufal.br/index.php/debateseducacao/article/view/I00 I I. Acesso em: dd mmm. aaaa.

\section{American Psychological Association (APA)}

Gallego Campos, F., \& Rovadoscki, S. (2020). Múltiplas leituras: adaptações fílmicas de contos de Edgar Allan Poe em aulas de Inglês. Debates em Educação, 12(Esp), 188-204. doi: https://doi.org// 0.28998/2 I75-6600.2020v I 2nEspp I 88-204 